\title{
MENSTRUAL DISORDERS IN ADOLESCENTS
}

\section{ABSTRACT}

The health problems of adolescents are very special. Menstrual disorders such as amenorrhea, abnormal/ excessive uterine bleeding, dysmenorrhea, and premenstrual syndrome are particularly common in adolescent girls. Although menstrual irregularities may be normal during the early postmenarchal years, pathological conditions require proper and prompt management. This article reviews the topic: menstrual disorders and discusses their etiologies, diagnosis and treatment modalities. It also reviews the normal and abnormal menstrual cycles. The knowledge of the normal menstrual cycle is very important in managing these disorders properly.

\section{Key Words: Adolescent, amenorrhea, dysfunctional uterine bleeding, dysmenorrhea, menstrual disorder, premenstrual syndrome.}

\section{INTRODUCTION}

Menstrual disorders are a common problem in adolescents. These disorders are often the source of anxiety for the patients and the families. The common menstrual disorders in adolescents are amenorrhea, abnormal/excessive uterine bleeding, dysmenorrhea, and premenstrual syndrome. ${ }^{1}$

The median age of menarche is 12.9 years. ${ }^{2}$ The length of the normal menstrual cycle is highly variable. Normal menstrual cycles are characterized by a cycle length of 28 days ( +7 days), a duration of flow of 4 days ( +2 days), and a blood loss of 40 $\mathrm{mL}(+20 \mathrm{~mL}){ }^{3}$ The mean volume of menstrual blood loss is $43 \mathrm{~mL}$, with a normal range of $20-80 \mathrm{~mL}^{4}$

Cycles are abnormal if they are longer than 8 to 10 days in duration or if more than $80 \mathrm{~mL}$ of blood loss occurs, particularly after the first 2 years from the onset of menarche. It is very difficult to quantify the blood loss however; soaking more than 25 pads or 30 tampons during a menstrual period is usually abnormal. Abnormal/irregular menstrual patterns are common during the first 2 years after menarche and the variability in cycle length is greater during adolescence than adulthood; thus greater irregularity is acceptable if significant anemia or hemorrhage is not present. 5

\section{The normal menstrual cycle}

Menstruation is the monthly physiologic shedding of the endometrium. The menstrual cycle is regulated by a combination of the hypothalamus, hypophysis, ovaries, and uterus. The hypothalamus and the pituitary gland regulate the reproductive hormones. The pituitary gland is often referred to as the master gland because of its important role in many vital functions, many of which require hormones. The hypothalamus first releases gonadotropin-releasing hormone $(\mathrm{GnRH}) . \mathrm{GnRH}$, in turn, stimulates the pituitary gland to produce follicle-stimulating hormone $(\mathrm{FSH})$ and luteinizing hormone (LH). The ovaries at the command of FSH and LH secrete estrogen and progesterone.

Address for correspondence : Dr. Ganesh Dangal

Binayak Maternity Hospital, Gausala, Kathmandu, Nepal

Email: gareshma@hotmail.com 
Normal menstruation results from progesterone withdrawal from estrogen-primed endometrium. Menstrual cycle is the result of a complex interaction between the various organs as shown in Fig.1. Dysfunction at any level can interfere with ovulation and the menstruation.

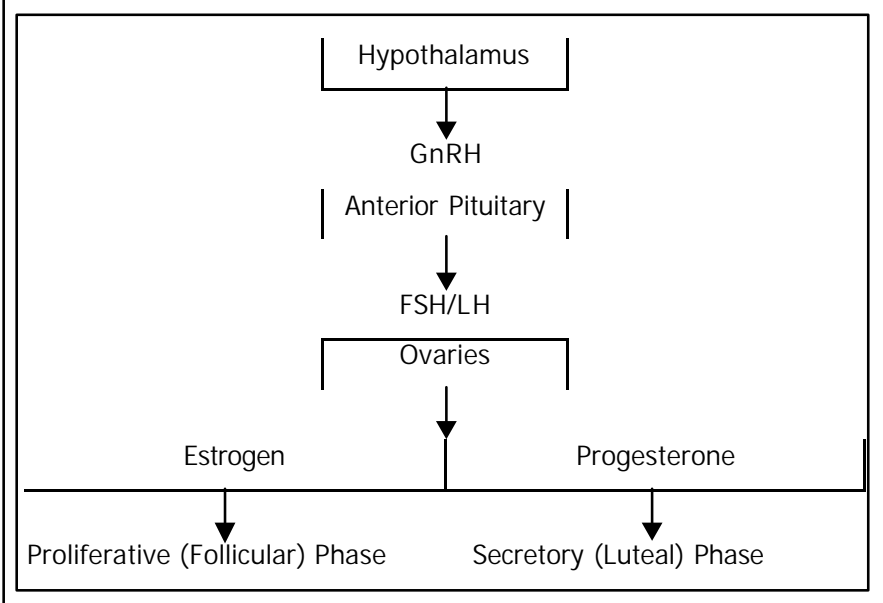

Fig.1 : Pathway of action of hormones for normal menstrual function. ${ }^{6}$

\section{Hormonal changes in the normal menstrual cycle}

During the follicular phase, release of GnRH stimulates the pituitary to secrete FSH and $\mathrm{LH}$, which then stimulate ovarian estrogen secretion ultimately inducing endometrial proliferation. With the start of each menstrual cycle, FSH stimulates several follicles to mature over a two-week period. Only one follicle becomes dominant, however, during a cycle. These follicles produce estrogen, which enters the bloodstream and reaches the uterus where it stimulates the endometrial cells to reproduce, therefore thickening the walls.

Estrogen levels reach their peak around the 14th day of the cycle. As estrogen levels peak, the pituitary gland releases increased amounts of LH. Ovulation occurs about 12 hours after the midcycle surge in LH. The luteal phase follows ovulation, and the corpus luteum secretes progesterone and estrogen. Progesterone inhibits endometrial proliferation and induces glandular changes. Without fertilization, the corpus luteum regresses, resulting in a decrease in progesterone and estrogen, and shedding of the endometrium (menses) 14 days after ovulation.

\section{Hormonal changes during anovulatory cycles}

Anovulatory cycles are common in the first 2 years after menarche because of the immaturity of the HPO axis..$^{5,7}$ Anovulation also can occur in a variety of pathological conditions. In anovulatory cycles, the follicular growth occurs with the stimulation from FSH; however, due to lack of LH surge, ovulation fails to occur. Consequently, no corpus luteum is formed and no progesterone is secreted. The endometrium continues its proliferative phase excessively. When the follicle involutes, estrogen levels drop and its withdrawal bleeding occurs. Most anovulatory cycles are regular with normal bleeding; however, the unstable proliferative endometrium can shed irregularly, resulting in prolonged heavy bleeding.

The adolescents have amenorrhea, dysmenorrhea, premenstrual syndrome and abnormal uterine bleeding as the common types of menstrual disorders which are dealt in detail below.

\section{Amenorrhea}

Adolescents frequently experience irregular menstrual bleeding patterns, which can include several consecutive months of amenorrhea. Amenorrhea-except that occurring before puberty, during pregnancy or early lactation, and after menopause-is pathologic. Amenorrhea may be caused by anatomic abnormalities; hypothalamic, pituitary, or other endocrine dysfunction; ovarian failure; or genetic defects (Table I).

Amenorrhea may be primary (never menstruated) or secondary (i.e., menarche, but no periods for 3 consecutive months). Primary amenorrhea is defined as the absence of the menses by 16 years of age in the presence of normal secondary sexual characteristics or by 14 years of age when there is no visible secondary sexual characteristics development. ${ }^{9}$ The American College of Obstetricians and Gynecologists recommends that a young woman consult her physician if she has not started to menstruate by the age of 16 , and/or if she has not begun to develop breast buds, pubic hair, or underarm hair by the age of 13 or 14.

A woman who has previously menstruated can develop secondary amenorrhea, which can be defined as the absence of menses for consecutive 3 months. Secondary amenorrhea is more common than primary one. The most common etiology is dysfunction of the hypothalamic-pituitary-ovarian (HPO) axis. A careful history, a detailed examination and appropriate investigations (hormonal assay, imaging and others) are necessary to diagnose these patients properly. The management depends on the etiologies of the problems and involves surgical correction, hormone replacement and other appropriate medical therapies accordingly.

\section{Amenorrhea without secondary sexual characteristics}

Abnormalities of the pituitary and hypothalamus and other endocrinopathies (thyroid disease and Cushing syndrome) may present with pubertal delay and low gonadotropin levels. Amenorrhea may be caused by problems at the pituitary gland, 
Table I : Causes of amenorrhea (Compiled from the Merck Manual) ${ }^{8}$

\begin{tabular}{|c|c|c|c|}
\hline Cause & Examples & Cause & Examples \\
\hline $\begin{array}{l}\text { Anatomic } \\
\text { abnormalities }\end{array}$ & $\begin{array}{l}\text { Asherman's syndrome } \\
\text { Cervical stenosis (rare) } \\
\text { Imperforate hymen } \\
\text { Male pseuohermaphroditism } \\
\text { Transverse vaginal septum } \\
\text { Vaginal and uterine aplasia }\end{array}$ & $\begin{array}{l}\text { Pituitary } \\
\text { dysfunction } \\
\text { (continued) }\end{array}$ & $\begin{array}{l}\text { Panhypopituitarism } \\
\text { Pituitary tumors(eg.Forbes- } \\
\text { Albright syndrome) } \\
\text { Psychomimetic drugs }\end{array}$ \\
\hline $\begin{array}{l}\text { Hypothalamic } \\
\text { dysfunction }\end{array}$ & $\begin{array}{l}\text { Anorexia nervosa } \\
\text { Excessive exercise } \\
\text { Hypothalamic chronic anovulation } \\
\text { Kallman's syndrome } \\
\text { Psychogenic factors, severe stress } \\
\text { Tumors } \\
\text { (eg.hamartomas,craniopharyngioma } \\
\text { s,gliomas) } \\
\text { Weight loss, malnutrition }\end{array}$ & Ovarian failure & $\begin{array}{l}\text { Autoimmune disorders } \\
\text { Chemotherapy and pelvic } \\
\text { radiation } \\
\text { Congenital thymic aplasia } \\
\text { Galactosemia } \\
\text { Gonadal dysgenesis }\end{array}$ \\
\hline \multirow[t]{2}{*}{$\begin{array}{l}\text { Pituitary } \\
\text { dysfunction }\end{array}$} & $\begin{array}{l}\text { Amenorrhea-galactorrhea } \\
\text { (hyperprolactinemia) } \\
\text { Benign pituitary adenoma } \\
\text { Hypopituitarism (eg.due to } \\
\text { Sheehan's syndrome, head trauma, } \\
\text { or neoplasm) } \\
\text { Isolated gonadotropin deficiency }\end{array}$ & $\begin{array}{l}\text { Other } \\
\text { endocrine } \\
\text { dysfunction }\end{array}$ & $\begin{array}{l}\text { Congenital adrenal hyperplasia } \\
\text { Cushing's syndrome } \\
\text { Drugs (antipsychotics, } \\
\text { antidpressants) } \\
\text { Hyperthyroidism } \\
\text { Hypothyroidism } \\
\text { Neoplasms producing } \\
\text { androgens, estrogens, or human } \\
\text { chorionic gonadotropin } \\
\text { Obesity } \\
\text { Polycystic ovary syndrome }\end{array}$ \\
\hline & & Genetic defects & $\begin{array}{l}\text { Androgen insensitivity } \\
\text { syndrome } \\
\text { Turner's syndrome }\end{array}$ \\
\hline
\end{tabular}

such as congenital hypopituitarism, tumor (pituitary adenoma), or infiltration (hemochromatosis). Prolactinoma is the most common pituitary tumor. They present with galactorrhea, headache, visual fields cuts, and amenorrhea. Elevated prolactin levels are characteristic. Craniopharyngioma is another tumor of the sella turcica that affects hypothalamicpituitary function, presenting with pubertal delay and amenorrhea.

Other disorders associated with galactorrhea and amenorrhea include hypothyroidism, breast stimulation, stress associated with trauma or surgery, and certain drugs (phenothiazines, opiates). Hypergonadotropic hypogonadism is caused by primary ovarian failure associated with elevated gonadotropin levels. An elevated FSH will establish the diagnosis.

Turner syndrome may cause ovarian failure and a lack of pubertal development. It is the commonest chromosomal abnormality causing gonadal failure and primary amenorrhea. ${ }^{9}$ Females with this syndrome have streak gonads, absence of one of the $\mathrm{X}$ chromosomes, and inadequate levels of estradiol. They do not initiate puberty or uterine development. It is characterized by short stature, webbed neck, widely spaced nipples, shield chest, high arched palate, congenital heart disease, renal anomalies, and autoimmune disorders (thyroiditis, Addison disease). It may not be diagnosed until adolescence, when pubertal delay and amenorrhea occur together.

Hypogonadotropic hypogonadism is caused by hypothalamic dysfunction or pituitary failure. Low or normal levels of $\mathrm{LH}$ and FSH will be present, and decreased estradiol levels may be present. Ovarian failure resulting from autoimmune disorders or exposure to radiation or chemotherapy may also cause amenorrhea with pubertal delay. Hypothalamic abnormalities associated with pubertal delay include Kallmann syndromes and others. This is associated with anosmia.

\section{Amenorrhea with secondary sexual characteristics}

In a pubertal female, pregnancy should be ruled out if there is sexual exposure and amenorrhea. Depot medroxyprogesterone (Depo-Provera), levonorgestrel implants (Norplant); and sometimes post-pill amenorrhea also occurs. Uterine synechiae (Asherman syndrome) should be suspected in amenorrheic patient with a history of abortion, dilation and curettage, or endometritis. 
Sheehan syndrome (pituitary infarction) is suggested by a history of intrapartum bleeding and hypotension in parous women. Anatomical abnormalities such as imperforate hymen, transverse vaginal septum, agenesis of the vagina may also present with amenorrhea.

Ovarian failure, prolactinomas, thyroid disease, and stress, athletes (excessive exercise), eating disorder (anorexia nervosa) may cause amenorrhea after normal pubertal development. Polycystic ovarian disease may also present with amenorrhea.

\section{Treatment}

Management of amenorrhea includes restoring ovulatory cycles if possible in the adolescent with constitutional delay and anovulation, replacing estrogen when necessary, reassurance to alleviate the tremendous anxiety of the patients, and reevaluation. Many of the treatment methods require surgery (for ovarian cysts or uterine problems) or specific therapies. Not all conditions can be treated, but any underlying condition that is treatable should be treated.

Treatment depends on the cause. The commonest cause of secondary amenorrhoea is pregnancy and this should always be excluded. Easing up on excessive exercise and eating a proper diet may bring on periods in teen athletes.

Polycystic ovary syndrome (PCOS) may respond to weight loss, and recently there has been interest in the use of insulinsensitizing agents, e.g. metformin. Clomiphene citrate is the first choice to induce ovulation. Other methods include exogenous gonadotropin, human purified FSH, ovarian wedge resection, and ovarian drilling. For those who are not hirsute, and do not desire pregnancy, an intermittent progestin (eg, medroxyprogesterone acetate 5 to $10 \mathrm{mg}$ /day po for 10 to 14 days) or oral contraceptives are used to reduce the increased risk of endometrial hyperplasia in PCOS patients.

Hypothyroidism is treated with levothyroxine. Hyperprolactinaemia often responds to bromocriptine. Prolactinomas will commonly shrink with medical therapy, but large tumours may need surgery. Other tumours of the pituitary, hypothalamus, ovary, and adrenal glands usually require surgery. Some genital tract malformations are also treated by surgery, e.g. haematocolpos. Hypothalamic amenorrhoea is treated with pulsatile GnRH. Amenorrhoea secondary to pituitary disease (excluding prolactinomas) are treated with gonadotrophins. Glucocorticoids should be used only for documented adrenal hyperfunction or enzyme defects in the steroidogenic pathway.

All women with low oestrogen levels should be considered for oestrogen replacement especially for prevention of osteoporosis. An adequate intake of calcium (1500 mg/day) and vitamin D (400 IU/day) is also advisable.

\section{Oligomenorrhea}

Infrequent or light menstrual cycles are known as oligomenorrhea. It is very common in early postmencharchal period and not usually worrisome. When girls first menstruate they often do not have regular cycles for a few years. In some women periods may occur every three weeks and in others, every five weeks. Flow also varies and can be heavy or light. Women should be concerned when periods come less than 21 days or more than 2 to 3 months apart, or if they last more than eight to ten days. Such events may indicate ovulation problems.

\section{Dysmenorrhea}

It is the cyclic menstruation pain in the lower abdomen usually associated with other gastrointestinal and neurological symptoms. It may be associated with pathology (secondary dysmenorrheal) or may be idiopathic in origin (primary dysmenorrhea-more prevalent). Dysmenorrhea is a common disorder that affects approximately $50 \%$ of menstruating women. ${ }^{10}$ The pain is thought to result from uterine contractions and ischemia, probably mediated by prostaglandins produced in secretory endometrium; therefore, primary dysmenorrhea is almost always associated with ovulatory cycles and usually appears within 1-2 years of menarche, when ovulatory cycles are established. This common disorder usually starts during adolescence and tends to decrease with age and after pregnancy.

Some women experience mild to moderate lower abdominal pain during mid-cycle (the $13^{\text {th }}-15^{\text {th }}$ day of the cycle), some times there is blood spotting also. This is because of the release of the ovum into peritoneal cavity and no treatment is required for this Mittelschmerz syndrome.

\section{Clinical features}

Lower abdominal pain is usually cramping or colicky but may be a dull constant ache and radiate to the lower back or legs and there is general malaise as well. The pain may start a few hours prior to or with menses, tends to peak after 24 hours, and usually subsides after 2 days. Sometimes endometrial casts (membranous dysmenorrhea) or clots are expelled. Headache, nausea, constipation or diarrhea, and urinary frequency are common; vomiting occurs occasionally. On examination the vital organs are normal. The pelvic organs are normal in primary dysmenorrhea. 
Secondary dysmenorrhea usually develops years after menarche and can occur with anovulatory cycles and this may be associated with uterine and pelvic pathology such as intrauterine contraceptive device (IUCD), endometriosis, pelvic inflammatory disease (PID), cervical stenosis, a submucosal fibroid or an endometrial polyp, etc. The pain occurs when the uterus attempts to expel tissue through the os. The pain of secondary dysmenorrhea often begins 1-2 weeks prior to menses and persists until a few days after the cessation of the bleeding.

\section{Treatment}

In case of primary dysmenorrhea, a woman should be assured that her reproductive organs are normal. Many do not need medications, but for women with significant problems, the most effective drugs are prostaglandin synthetase inhibitors (eg, ibuprofen, mefenamic acid) as the pain is caused by prostaglandins induced contraction of the uterus during ovulatory cycles. Prostaglandin synthetase inhibitors are effective in approximately $80 \%$ of cases. ${ }^{11,12}$ A drug may be more effective if started 24 to $48 \mathrm{~h}$ before and continued 1 or 2 days after menses begins. If pain continues to interfere with normal activity, suppression of ovulation with low-dose combined oral contraceptive pill is effective. For the patient with primary dysmenorrhea who has no contraindications to combined pills or who desires contraception, the pill is the agent of choice. More than $95 \%$ will have relief with the pills. ${ }^{13}$

If nonsteroidal anti-inflammatory drug (NSAID) fails, oral contraceptive pills can be used for 3-6 months. Antiemetics may be used, if there is nausea and vomiting. Adequate rest, sleep, hot fomentation, acupuncture and regular exercise may help in some women. In case of secondary dysmenorrhea, the first line of treatment is medical (eg, prostaglandin synthetase inhibitors, oral contraceptives, danazol, progestins). The treatment of the specific underlying disorder is very important. If possible, the underlying disorder or anatomic abnormality is corrected, thus relieving symptoms. Dilation of a narrow cervical os may give 3 to 6 months of relief (and allows diagnostic curettage if needed). Other surgical measures (e.g. myomectomy, polypectomy, or dilation and curettage) may be needed in some patients. But these are usually not required for adolescent girls. Presacral neurectomy and division of the sacrouterine ligaments may help selected patients.

\section{Premenstrual Syndrome}

The emotional fluctuation that an adolescent girl experiences about a week before the expected menstruation is known as the premenstrual syndrome (PMS) or tension. This happens due to the changes in the blood levels of estrogen as well as progesterone. Majority of menstruating women experience some form of PMS. These problems are more likely to trouble women in their $20 \mathrm{~s}$ and $30 \mathrm{~s}$. The physical and emotional changes they experience may be more or less intense with each menstrual cycle.

The main symptoms are headache, nausea, gain in weight, and tenderness of breasts, associated with mood swings, a swollen abdomen, food cravings and fatigue. Nervousness, irritability, emotional instability, anxiety, depression, edema, and mastalgia, usually disappearing a few hours after onset of menses also characterize it. Premenstrual syndrome (PMS) appears to be related to fluctuations in estrogen and progesterone. They may cause transitory fluid retention, which seems to explain some PMS symptoms.

\section{Causes}

Cyclic hormonal fluctuations seem to be an important cause. One clue to the cause may be traced to fluctuations of serotonin, a brain neurotransmitter that is thought to play a crucial role in mood states, especially depression. Insufficient amounts of serotonin may contribute to other symptoms of PMS, such as fatigue, food cravings and sleep problems. Few patients with severe PMS have undiagnosed depression. Stress also may aggravate some of the symptoms, but alone is not a cause. Some symptoms have been linked to low levels of vitamins and minerals. Eating a lot of salty foods, which may cause fluid retention, and drinking alcohol and caffeinated beverages also may cause mood and energy level disturbances.

\section{Clinical features}

The symptoms vary from woman to woman and from cycle to cycle. In many, symptoms are significant but brief and not disabling; in others, normal functioning is disturbed. Symptoms last a few hours to few days, usually disappearing when menses begins. In some, they may persist through and after menses. Sometimes, when menstruation begins significant dysmenorrhea can occur and is more common among adolescents and tends to diminish with age.

The most common complaints are mood alteration and irritability, nervousness, agitation, anger, crying spells, insomnia, difficulty in concentrating, lethargy, depression, and severe fatigue. Fluid retention may cause edema, transient weight gain, oliguria, and breast fullness and pain. Neurovascular symptoms include headache, vertigo, syncope, paresthesias of the extremities, easy bruising, and palpitation. Epilepsy may be aggravated. Gastro-intestinal symptoms 
include abdominal bloating, constipation, nausea, vomiting, and appetite changes and food cravings. Joint or muscle pain and backache may occur. Acne and aggravation of other skin disorders may also occur. Most women with PMS experience only a few of these problems. For some the problems are severe enough to affect their daily routines and activities. The symptoms usually disappear as the menstrual period begins. There are no unique physical findings or laboratory tests to positively diagnose PMS.

\section{Treatment}

If the PMS symptoms are seriously affecting patients' health and daily activities, it needs treatment. Managing PMS with lifestyle changes can be tried. If the emotional disturbance remains limited to the mood fluctuations, it can be controlled with proper diet (e.g. low fats, high protein), taking adequate rest and sleep. Psychological counseling may help. Some times the syndrome is accompanied by episodes of epileptic fit and lowered blood sugar. Such patients should be treated with appropriate medical therapy. Symptomatic treatment is often useful. Reducing salt and salty foods and using a diuretic, starting just before symptoms are expected may relieve fluid retention. Counseling may help the woman cope with PMS, and her activities can be modified to reduce stress. Smaller, more frequent meals may reduce bloating and the sensation of fullness. Foods rich in calcium and foods high in complex carbohydrates (fruits, vegetables) are useful. Avoiding caffeine and alcohol is sometimes helpful.

Common medications for PMS include nonsteroidal antiinflammatory drugs (NSAIDs), hormones, and antidepressants. The use of antidepressants may be limited to the two weeks before menstruation begins.Hormonal therapy is effective in some patients. Oral contraceptives; progesterone for 10 to 12 days premenstrually; a long-acting progestin (e.g., medroxyprogesterone acetate $200 \mathrm{mg}$ IM every 2 to 3 monthly); or a gonadotropin-releasing hormone agonist with low-dose estrogen-progestin "add-back" therapy to eliminate cyclic changes can be used. Benzodiazepine may be used for irritability, nervousness, especially if patients cannot alter their stressful environ. Selective serotonin reuptake inhibitors (eg, fluoxetine $20 \mathrm{mg}$ orally daily, sertraline $50 \mathrm{mg}$ daily) are the most effective drugs in the management of psychologic and physical premenstrual symptoms. ${ }^{14}$ Aerobic activity, brisk walking, cycling, swimming can help improve overall health and alleviate symptoms such as fatigue and a depressed mood. Deep-breathing exercises to help reduce headaches, anxiety or insomnia. Calcium, magnesium, vitamin B-6, vitamin $\mathrm{E}$ are also known to be effective in soothing the symptoms of PMS.

\section{Abnormal uterine bleeding}

Abnormal/excessive uterine bleeding is a common and a frustrating problem even in adolescents. Determination of the prevalence of abnormal uterine bleeding is difficult however $9 \%$ to $30 \%$ of reproductive-aged women have menstrual irregularities requiring medical evaluation. ${ }^{15}$ Accurate diagnosis of it can be challenging. A detailed history and a complete physical examination are indispensable in the evaluation, since many cases provide no sensitive physical abnormalities or useful laboratory findings.

Vast majority of abnormal bleeding in adolescents is caused by immaturity of the hypothalamic-pituitary-ovarian (HPO) axis resulting in anovulatory menstrual cycles and thereby dysfunctional in origin. In some, the bleeding is secondary to problems of pregnancy, uterine pathology, exogenous hormone use and systemic bleeding disorders. Although most episodes of abnormal bleeding do not cause acute medical complications, bleeding can be traumatic for young patients and their families. Here, the most frequent etiologies, diagnosis and treatment modalities of abnormal bleeding in adolescents are discussed.

Abnormal uterine bleeding may occur in women of all ages, it is a particularly common issue for adolescents and it can be caused by a wide variety of disorders and may represent a normal physiological state, and observation alone may be warranted. Alternatively, the bleeding can be a sign of a serious underlying condition necessitating aggressive treatment that could include a major procedure. ${ }^{16}$

Dysfunctional uterine bleeding is a frequent gynecological problem in women of all ages ${ }^{17}$ and particularly common during adolescence and perimenopausal periods. It is a diagnosis of exclusion. This diagnosis can only be made in the absence of hirsutism or galactorrhea as revealing symptoms of functional ovarian hyperandrogenism, polycystic ovary syndrome, late form of congenital adrenal hyperplasia or hyperprolactinemia; ovarian failure. Coagulation disorders must always be excluded. DUB is defined as abnormal and excessive endometrial bleeding without structural pathology. ${ }^{18}$ Chronic anovulation may also be associated with thyroid or prolactin disorders, premature ovarian failure, adult-onset congenital adrenal hyperplasia, or polycystic ovary syndrome. ${ }^{19}$ Some common causes of hypothalamic anovulation are weight loss or gain, eating disorders, stress, chronic illness, and excessive exercise. Women with chronic anovulation that is not attributable to any of these causes are considered to have idiopathic chronic anovulation. ${ }^{20}$

The following definitions describe menstrual patterns associated with abnormal uterine bleeding (Table II). 
Table II : Types and characteristics of abnormal uterine bleeding (Compiled from Petrozza and Poley ${ }^{19}$ and Speroff et al. ${ }^{21}$ )

\begin{tabular}{l|l}
\hline \multicolumn{1}{c|}{ Type } & \multicolumn{1}{c}{ Characteristics } \\
\hline Oligomenorrhea & Cycle length $>35$ days \\
\hline Polymenorrhea & Cycle length $<21$ days \\
\hline Amenorrhea & Absence of menses for 6 months or three cycles \\
\hline Menorrhagia & Regular cycles; excessive flow, duration \\
\hline Metrorrhagia & Irregular cycles \\
\hline Menometrorrhagia & Irregular cycles; excessive flow, duration \\
\hline
\end{tabular}

Table III : Selected causes in abnormal uterine bleeding in adolescents (Modified from Kilbourn and Richards ${ }^{22}$ )

Hormonal
Immaturity of HPO axis
Anovulation syndromes
Estrogen breakthrough/ withdrawal
Ovarian failure
Exogenous hormones
Oral contraceptives
Depot forms of progesterone
Coagulation disorders
Von Willebrand's disease
Thrombocytopenias
Leukemias
Coagulopathies-hepatic failure, warfarin therapy
Trauma
Sexual abuse,
Accidental injury
Inflammation from STD
Systemic disease
Polycystic ovary syndrome
Hypothyroidism
Hyperprolactinomas
Androgen excess disorders

\section{Causes of abnormal bleeding in adolescents}

The causes that can give rise to abnormal uterine bleeding vary based on the age and reproductive status of the patient. The differential diagnoses in adolescents with abnormal uterine bleeding are extensive and there are many causes (Table III). The usual causes of abnormal uterine bleeding in an adult female are much different from the usual causes in an adolescent.

Structural pathology such as benign pelvic lesions and malignancy and pregnancy related disorders like ectopic pregnancy, gestational trophoblastic disease are uncommon in adolescents.

All adolescents with menorrhagia severe enough to require hospitalization or significantly reduce hemoglobin levels (to $<10$ $\mathrm{g} / \mathrm{dL}$ ) should undergo evaluation for coagulopathy. Von Willebrand's disease, a defect in platelet adhesion and a deficiency of factor VIII, is the most common bleeding disorder, affecting about $1 \%$ of the population. Diseases causing thrombocytopenia include idiopathic thrombocytopenic purpura, leukemia, and aplastic anemia. In adolescents, the prevalence of a primary coagulation disorder requiring hospitalization for abnormal uterine bleeding ranges from $3 \%$ to $20 \% .^{23}$

In women with evidence of ovulation, abnormal uterine bleeding should prompt suspicion of benign pelvic lesions. Hypothyroidism is an uncommon, although important, cause of metrorrhagia or menorrhagia even in adolescents. In about $25 \%$ of cases of menstrual abnormalities, an organic or pathologic etiology such as pregnancy complications, neoplasm, infection, or disease conditions such as a coagulation disorder can account for the abnormality. ${ }^{24}$

The term DUB describes the syndrome of abnormal menstrual patterns caused by hormonal imbalances. In majority of cases, it is secondary to anovulation, which is more common at the extremes of reproductive age. Patients with anovulatory cycles typically do not experience premenstrual tension syndromebreast discomfort, increased mucoid vaginal discharge, or premenstrual cramping and bloating-characteristic of ovulatory 
cycles (Table IV). The most common causes of anovulatory cycles include polycystic ovary syndrome (PCOS), hypothalamic amenorrhea, premature ovarian failure, and hyperprolactinemia. ${ }^{25}$ Approximately $90 \%$ of cases in nonpregnant adolescents are secondary to DUB. ${ }^{26}$ DUB may also occur with ovulatory cycles as a result of insufficiency of the corpus luteum (luteal phase defect). Periods are usually regular in timing but duration of menses is increased. This is less common in adolescents than in adult women.

The following information is useful to determine whether the bleeding is ovulatory or anovulatory in nature and, therefore, helps in the proper management (Table IV).

In rare cases, coagulation disorders may be the cause of heavy bleeding. ${ }^{27}$ Heavy bleeding can eventually lead to iron deficiency anaemia. ${ }^{28}$ These include diseases that affect platelet number or function (such as idiopathic thrombocytopenic purpura, von Willebrand's disease, or leukemia), as well as disruption of intrinsic coagulation factors (hereditary coagulopathies, hepatic or renal failure). Medications such as aspirin or warfarin may also contribute to the problem of bleeding. Phenytoin, phenothiazines, steroids, tricyclic antidepressants, and lithium may also contribute to abnormal menses.

\section{Polycystic ovary syndrome (PCOS)}

Polycystic ovary syndrome - the association of hyperandrogenism (hirsutism, acne, etc) and chronic anovulation in women without specific underlying diseases of the adrenal or pituitary glands - is one of the most common endocrine disorders. ${ }^{29}$ The classic syndrome complex of oligomenorrhea, hirsutism, obesity, and polycystic ovaries was first described in 1935 by Stein and Leventhal. It is now appreciated that there is a clinical spectrum of related androgen excess syndromes in many women with anovulatory cycles, in which any of these four signs may be minimal or absent. ${ }^{30}$
There is hypersecretion of LH resulting in a state of chronic anovulation. Hyperandrogenism presents as hirsutism, acne, or male-pattern alopecia. Anovulation manifests itself as menstrual disturbance - amenorrhea, oligomenorrhea, or dysfunctional uterine bleeding - and infertility. Obesity is common but not usually a presenting symptom. In many cases, a history of menstrual disturbance dates back to the menarche. Hirsutism and obesity may be present in adolescent girls, even before the menarche. Associated pathologies include insulin resistance syndromes, cardiovascular disease, and structural abnormalities of the ovaries.

\section{Diagnostic Evaluation \\ History taking}

Age of menarche, detailed description of the pattern of bleeding (the frequency, duration, and severity of flow), current medications or hormonal contraceptives, previous gynecologic history, family history, desire for contraception, sexual history, likelihood of pregnancy, and the presence of chronic medical problems, risk factors for sexually transmitted diseases, and tobacco use are all important aspects of the patient's history. It is also crucial to determine if the bleeding is acyclic or cyclic, the latter being more consistent with ovulation.

\section{Physical examination}

Evidence of androgen excess (hirsutism, acne, etc.), evidence of hypo or hyperthyroidism, thyromegaly, presence of galactorrhea (hyperprolactinemia) and many other physical findings may help arrive at a diagnosis.Evidence of liver disease, eating disorders, and coagulopathies should be sought for in adolescents. Although a thorough pelvic examination is essential in older women; it is rarely needed in the adolescents. In young women during the 5 years following menarche and women with breakthrough bleeding who are using hormonal contraceptives, an internal examination is not necessary except if there is contact bleeding or if the possibility of an STD cannot be excluded. ${ }^{7,31,32}$

Table IV : Characteristics of ovulatory and anovulatory menstrual cycles

Ovulatory cycles

Regular cycle length

Presence of premenstrual symptoms

Dysmenorrhea

Breast tenderness

Change in cervical mucus

Mittleschmertz

Biphasic temperature curve

Positive result from use of luteinizing-hormone predictor kit

Anovulatory cycles

Unpredictable cycle length

Unpredictable bleeding pattern

Frequent spotting

Infrequent heavy bleeding

Monophasic temperature curve 
Table V : Laboratory and imaging studies for abnormal uterine bleeding inadolescents

\begin{tabular}{|c|c|c|c|}
\hline & $\begin{array}{l}\text { Common routine laboratory } \\
\text { studies }\end{array}$ & $\begin{array}{l}? \\
?\end{array}$ & $\begin{array}{l}\text { Complete blood count } \\
\text { Prothrombin time (PT), activated partial thromboplastin } \\
\text { time (aPTT), and bleeding time } \\
\text { Pregnancy test } \\
\text { Cervical cultures for chlamydia and gonorrhea }\end{array}$ \\
\hline 2. & $\begin{array}{l}\text { Secondary laboratory } \\
\text { studies for patients - } \\
\text { unresponsive to therapy; } \\
\text { and having findings } \\
\text { suggestive of a systemic } \\
\text { disorder }\end{array}$ & $\begin{array}{l}? \\
? \\
? \\
?\end{array}$ & $\begin{array}{l}\text { Thyroid-stimulating hormone (TSH) test } \\
\text { Fasting glucose } \\
\text { Prolactin } \\
\text { LH, FSH, and androgen levels (Dehydroepiandrosterone } \\
\text { sulfate (DHEAS) and free testosterone) } \\
\text { Adrenal function tests (eg, cortisol, 17-alpha } \\
\text { hydroxyprogesterone [17-OHP]) }\end{array}$ \\
\hline 3. & $\begin{array}{l}\text { Imaging studies for women } \\
\text { who do not respond to } \\
\text { routine therapy }\end{array}$ & ? & $\begin{array}{l}\text { Pelvic ultrasound is useful for demonstrating structural } \\
\text { abnormalities of the uterus, endometrial thickness; and } \\
\text { adnexal areas } \\
\text { MRI /CT scanning are only rarely is superior to } \\
\text { ultrasonography }\end{array}$ \\
\hline
\end{tabular}

\section{Diagnostic testing}

In most cases, investigation is limited to a complete blood cell count (Table V). Abnormal leukocyte count may indicate leukemias. The level of hemoglobin will signify the severity of the menorrhgia and also guide for the urgency of the treatment. Sexually active adolescents who have abnormal uterine bleeding should have a urine or serum pregnancy test. Other tests are done only if indicated by the history and physical findings. Diagnostic tests for systemic diseases such as hypothyroidism, hyperthyroidism, renal disease, malnutrition, etc., may be used as clinically indicated. ${ }^{33}$

Testing for sexually transmitted diseases may be indicated in sexually active adolescents. Adolescents who are not pregnant do not require additional workup. In this group, if a cause is not uncovered during the evaluation described earlier, a diagnosis of dysfunctional uterine bleeding is assumed, and treatment may be prescribed accordingly. Von Willebrand's disease should be suspected with excessive bleeding at menarche and quantitative or functional assays for von Willebrand's factor, bleeding time, etc, are helpful in diagnosing it. Coagulation studies (PT/PTT) and platelet count are helpful in cases of thrombocytopenias.

Ultrasound may be useful in some to ascertain the normalcy of the reproductive organs and therefore valuable in some adolescents but invasive diagnostic modalities like D \& C, hysteroscopy and Pap smears are not applicable to the adolescents unlike older women in whom these are sometimes very useful.

In polycystic ovary syndrome, a properly timed LH: FSH ratio (> 2:1) is usually present, along with clinical and/or laboratory findings of hyperandrogenism (elevated free testosterone levels) and chronic anovulation (in the absence of secondary causes such as hyperprolactinemia, adult-onset congenital adrenal hyperplasia, and neoplasm).

\section{Therapeutic Interventions}

Adolescents require rapid, safe and effective treatment for their abnormal bleeding. Most cases of abnormal bleeding in adolescents fall under the category of DUB. If a specific etiology is identified, treatment of the underlying cause is necessary, e.g. thyroid hormone replacement in hypothyroidism and bromocriptine for hyperprolactinemia. Patients taking exogenous hormones (e.g. oral contraceptives) may benefit from a change in their regimen.

The aims in treatment of DUB are to control bleeding, prevent recurrences, and preserve fertility. ${ }^{34}$ Dysfunctional uterine bleeding can be treated medically or surgically. Medical treatment (Table VI) consists of antifibrinolytic tranexamic acid, NSAID's, the combined contraception pill, progestogen, danazol, or analogues of GnRH. The levonorgestrel releasing intra uterine device is also effective in the treatment of dysfunctional uterine bleeding. ${ }^{35}$

In the adolescents, anovulatory cycles may simply be observed while awaiting maturation of the HPO axis and reassurance is provided. Regular cycling with a progestogen, or combined oral contraceptives (OCP), may be used to regulate the menses. Progestogen therapy is administered cyclically either in the second half (luteal phase treatment from the $15^{\text {th }}$ to the $25^{\text {th }}$ day) or throughout the menstrual cycle (whole cycle treatmentfrom the 5 th to the $25^{\text {th }}$ day). 
Table VI : Drugs commonly used in treatment of DUB (Adapted from Dangal $G^{6}$ )

\begin{tabular}{cl}
\hline$?$ & Progestogens- Oral, Depot, Injection \\
$?$ & Combined OC pills(OCP) - Low-dose OCP \\
$?$ & NSAID's- Ibuprofen, Mefenamic acid \\
$?$ & Estrogens - Premarin \\
$?$ & Antigonadotrophin- Danazol \\
$?$ & Antifibrinolytic- Tranexamic acid \\
$?$ & GnRH analogues- Leuprolide, Nafarelin \\
$?$ & Ethamsylate \\
$?$ & Anti-anemics- Iron, Folate \\
\hline
\end{tabular}

Table VII : Medical treatment options for DUB (Adapted from Speroff et al $^{21}$ )

\begin{tabular}{c|l|l}
\hline Bleeding & \multicolumn{1}{|c}{ Treatment option } & \multicolumn{1}{c}{ Comments } \\
\hline Acute & $\begin{array}{l}\text { Oral contraceptive, 1 tablet PO } \\
\text { bid or tid X 7d; allow withdrawal } \\
\text { bleed, then 1 tablet PO qd X 3 mo }\end{array}$ & $\begin{array}{l}\text { Use low-dose (35-microgram) } \\
\text { monophasic formulation; some } \\
\text { clinicians omit withdrawal bleed } \\
\text { to avoid exacerbating anemia }\end{array}$ \\
\hline & $\begin{array}{l}\text { Conjugated estrogen (Conjugase, } \\
\text { Premarin), 25 mg IV q4-6h X 1 } \\
\text { day or 1.25 mg PO q4-6h X 1 } \\
\text { day, then oral contraceptive as } \\
\text { above }\end{array}$ & $\begin{array}{l}\text { All estrogen-only therapy must be } \\
\text { followed by progestin coverage }\end{array}$ \\
\hline Chronic & $\begin{array}{l}\text { Oral contraceptive, 1 tablet PO qd } \\
\text { Medroxyprogesterone acetate, 10 } \\
\text { mg PO qd X 10 days/mo }\end{array}$ & $\begin{array}{l}\text { Older women should use 20- } \\
\text { microgram pills } \\
\text { Bleeding occurs 2-7 days after } \\
\text { last dose }\end{array}$ \\
\hline $\begin{array}{l}\text { Clomiphene citrate (Ovofar, } \\
\text { Clomid), 50-150 mg qd on days } \\
5-9\end{array}$ & $\begin{array}{l}\text { Use for patients who wish to } \\
\text { become pregnant }\end{array}$ \\
\hline
\end{tabular}

Table VIII : Management strategy in adolescent DUB (Compiled from Sharma JB ${ }^{29}$ )

\begin{tabular}{|c|c|c|c|}
\hline $\begin{array}{l}\text { Age } \\
\text { (years) }\end{array}$ & D and C or hysteroscopy & $\begin{array}{l}\text { Conservative/Medical } \\
\text { (hormone, anti-PG, } \\
\text { or antifibrinolytic) }\end{array}$ & Hysterectomy \\
\hline Under 20 & $\begin{array}{l}\text { Rarely, only if bleeding is } \\
\text { severe or non responsive }\end{array}$ & $\begin{array}{l}\text { Always, if bleeding is } \\
\text { recurrent or severe }\end{array}$ & Never \\
\hline
\end{tabular}

When bleeding is acute, heavy and the patient is hypovolemic, she should undergo volume resuscitation, be hospitalized, and be given high-dose intravenous estrogen ${ }^{34}$ (Table VII). Usually, the bleeding is controlled within 24 hours and the patient is switched to oral combined pills for 21-25 days. An alternative is to start treatment with combination estrogen/progestin preparations (OCP) 3-4 tablets per day with eventual tapering of the dose over 3-4 weeks.

The hemodynamically stable patient with acute heavy bleeding should also be treated with conjugated estrogen. The use of low-dose oral contraceptives (Table VII) is very convenient. She should continue to take the OC pills for at least another 3 months and then undergo reevaluation. ${ }^{21}$

Nonsteroidal anti-inflammatory drugs (NSAIDs) have been shown to reduce the bleeding via antiprostaglandin effects. ${ }^{34}$ They reduce menstrual blood loss and may be of greatest benefit in ovulatory DUB where the amount of prostanoid release is higher. They may be used alone or in combination with hormonal manipulation. Their use may be generally limited to the first 3 days.

Tranexamic acid can be used if NSAIDs are insufficiently effective. ${ }^{36}$ This drug, an antifibrinolytic, reduces bleeding by approximately $45 \%$ but does have side effects, especially nausea, dizziness, and diarrhoea. As with NSAIDs, tranexamic acid is taken during the first 3 days of menstruation. The dose is $1,000 \mathrm{mg} 3$ times daily.

Danazol and the gonadatrophin-releasing hormone analogues (the second line drugs) are highly effective, but their sideeffects make them suitable only for short-term use. ${ }^{37}$ Danazol is a synthetic agent with antiestrogenic and weak androgenic activities. ${ }^{38}$ Gonadotropin-releasing hormone agonists (leuprolide, nafarelin, and goserelin) work by disrupting the 
pulsatile release of hypothalamic GnRH. They down-regulate pituitary synthesis of FSH and LH and induce "medical castration". Their action results in induction of amenorrhea or reduction of menorrhagia. Unpleasant side effects (nausea, etc.) and expense limit the usage of these agents.

Surgical treatments include dilatation and curettage, hysterectomy or hysteroscopic endometrial ablation ${ }^{35,40-43} \mathrm{But}$ these are generally not needed and not recommended for the adolescents (Table VIII). Rarely will an adolescent require D and $\mathrm{C}$.

\section{CONCLUSION}

Menstrual disorders like amenorrhea, dysmenorrhea, premenstrual syndrome and abnormal uterine bleeding are very common during the early postmenarchal years. Proper understanding of the normal menstrual cycle is necessary to pinpoint the causes of these disorders and aids in the judicial management of them. An accurate diagnosis obtained by thorough history, complete physical examination and focused investigations in these adolescents is mandatory to direct appropriate management. The physician must always consider the adolescent's sensitivity and vulnerability in evaluating and treating various disorders of menstruation.

\section{REFERENCES}

1. MCEvoy M, Chang J, Coupey SM. Common menstrual disorders in adolescence: nursing interventions. Am J Matem Child Nurs 2004; $29(1): 41-9$.

2. Demir SC, Kadayyfcy TO, Vardar MA, Atay Y. Dysfunctional uterine bleeding and other menstrual problems of secondary school students in Adana, Turkey. J Pediatr Adolesc Gynecol $2000 ; 13(4): 171-5$.

3. Brenner PF. Differential diagnosis of abnomal uterine bleeding. Am J Obstet Gynecol 1996; 175 (3 part 2) : 766-9.

4. Spellacy WN. Abnomal bleeding. Clin Obstet Gynecol 1983; $26(3): 702-9$.

5. Hillard PA. Benign diseases of the female reproductive tract: symptoms and signs. In: Berek JS, Adashi EY, Hillard PA (eds). Novak's gynecology. $12^{\text {th }}$ edn. Baltimore: Williams and Wilkins, $1996 ; 331-97$.

6. Dangal G. Dysfunctional uterine bleeding and its management strategy. J Nepal Med Assoc 2001; 40 (138) : 98-106.

7. Simmons PS. Common gynecologic problems in adolescents. Prim Care 1988; 11: 629-42.

8. Beers MH, Berkow R (eds). The Merck manual of diagnosis and therapy. 17th edn. USA: John Wiley \& Sons, 1999; 19232070 .
9. Scherzer WJ, McClamrock H. Amenorrhea. In: Berek JS, Adashi EY, Hillard PA (eds). Novak's gynecology. $12^{\text {th }}$ edn. Baltimore: Williams and Wilkins, 1996; 808-32.

10. The ACOG American College of Obstetricians and Gynecologists. Dysmenormea. Technical bulletin. Washington, DC: ACOG, 1983; 63.

11. The Medical Letter: drugs for dysmenorrhea. Med Lett Drugs Ther 1979; 21:81-4.

12. Filler WW, Hall WC. Dysmenorrhea and its therapy. Am J Obstet Gynecol 1970; 106:104-9.

13. Chan WY, Dawood MY. Prostaglandin levels in menstrual fluid of dysmenorrheic and non-dysmenorrheic subjects with or without oral contraceptive or ibuprofen therapy. Adv Prostaglandin Thromboxane Res 1980; 8:1443-7.

14. Stotland NL. Common psychiatric problems. In: Berek JS, Adashi EY, Hillard PA (eds). Novak's gynecology. $12^{\text {th }}$ edn. Baltimore: Williams and Wilkins, 1996; 299-328.

15. Coulter A, Bradlow J, Agass M, Martin-Bates C, Tulloch A. Outcomes of referrals to gynaecology outpatient clinics for menstrual problems: an audit of general practice records. $B r$ J Obstet Gynaecol. 1991; 98:789-96.

16. Bayer SR, DeCherney AH. Clinical manifestations and treatment of dysfunctional uterine bleeding. JAMA, 1993; 269: 1823-8.

17. Dangal G. A study of endometrium of patients with abnormal uterine bleeding at Chitwan valley. Kathmandu Univ Med J 2003; 1 (2) : 110-2.

18. Polaneczky MM, Slap GB. Menstrual disorders in the adolescent: dysmenorrhoea and dysfunctional uterine bleeding. Pediatr Rev 1992; 13: 83-7.

19. Petrozza J, Poley K. Dysfunctional uterine bleeding. In: Curtis MG, Hopkins MP (eds). Glass's office gynecology. 5th edn. Baltimore: Williams \& Wilkins, 1999; 241-64.

20. Oreil KA, Schrager S. Abnormal uterine bleeding. Am Fam Physician 1999; 60 (5) :1371-82.

21. Speroff L, Glass RH, Kase NG (eds). Dysfunctional uterine bleeding. In: Clinical gynecologic endocrinology and infertility. 5th edn. Baltimore: Williams \& Wilkins, 1994:575-93.

22. Kilboum CL, Richards CS. Abnomal uterine bleeding: diagnostic considerations, management options. Postgrad Med 2001; 109 (1) : 137-50.

23. Bravender T, Emans SJ. Menstrual disorders: dysfunctional uterine bleeding. Pediatr Clin North Am 1999; 46 (3) : 545-53.

24. Smith CB. Pinpointing the cause of abnomal uterine bleeding. Womens Health Prim Care 1998; 1:835-44.

25. ACOG Practice Bulletin. Management of infertility caused by ovulatory dysfunction. Obstet and Gynecol 2002; 99 (2) :34758.

26. Dealy MF. DUB in adolescents. Nurse Pract 1998; 23:12-25. 
27. Kadir RA, Economides DL, Sabin CA, Owens D, Lee CA. Frequency of inherited bleeding disorders in women with menorrhagia. Lancet 1998; 351:485-9.

28. Hallberg L, Hogdahl A, Nilsson L, Rybo G. Menstrual blood loss - a population study. Variation at different ages and attempts to define nomality. Acta Obstet Gynecol Scand 1966; 45:32051 .

29. Zawadzki JK, Dunaif A. Diagnostic criteria for polycystic ovary syndrome: towards a rational approach. In: Dunaif A, Givens $\mathrm{JR}$, Haseltine FP, Merriam GR (eds). Polycystic ovary syndrome. Oxford, England: Blackwell Scientific, 1992:377-84.

30. Dawood MY. Menstrual disorders. Patient Care-Supplement Medical Economics Publishing 1992:1-21.

31. Hein $\mathrm{K}$. The first pelvic examination and common gynecological problems in adolescent girls. Women Health 1984; 9:47-63.

32. Johnson CA. Making sense of dysfunctional bleeding. Am Fam Physician 1991; 44:149-57.

33. Galle PC, McRae MA. Abnomal uterine bleeding. Finding and treating the cause. Postgrad Med 1993; 93:73-81.

34. Chuong CJ, Brenner PF. Management of abnormal uterine bleeding. Am J Obstet Gynecol 1996; 175 (3 part 2) :787-92.

35. Bongers MY; Mol BW; Brolmann HA. Current treatment of dysfunctional uterine bleeding. Maturitas 2004; 47 (3):15974.
36. Van Eijkeren MA, Christiaens GC, Scholten PC, Sixma JJ. Menorrhagia: current drug treatment concepts. Drugs 1992; 43:201-9.

37. Irvine GA, Cameron IT. Medical management of dysfunctional uterine bleeding. Baill lieres Best Pract Res Clin Costet Gynaecol 1999; $13(2): 189-202$.

38. Roesnfeld JA. Treatment of menorrhagia due to dysfunctional uterine bleeding. Am Fam Physician 1996; 53: 165-72.

39. Sharma JB. Management strategies in dysfunctional uterine bleeding. Obstetrics and Gynaecology Today 2000; 5 (11) : 3946.

40. Erian J. Endometrial ablation in the treatment of menormagia. Br J Obstet Gynaecol 1994; 101:19-22.

41. Pinion $\mathrm{SB}$, Parkin $\mathrm{DE}$, Abramovich $\mathrm{DR}$, et al. Randomised trial of hysterectomy, endometrial laser ablation and transcervical resection for dysfunctional uterine bleeding. BMJ 1994; 309:979-83.

42. Gannon MJ, Holt EM, Fairbank J, Fitzgerald M, Milne MA, Crystal AM, et al. A randomised trial comparing endometrial resection and abdominal hysterectomy for the treatment of menorrhagia. BMJ 1991; 303:1362-4.

43. DeCherney A, Polan ML. Hysteroscopic management of intrauterine lesions and intractable uterine bleeding. Obstet Gynecol 1983; 61:392-7.

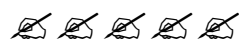

